\title{
Newly build tract for measuring regenerative heat exchangers
}

\author{
Stanislav Sehnalek ${ }^{1, *}$ and Martin Zalesak ${ }^{1, * *}$ \\ ${ }^{1}$ Tomas Bata University in Zlin, Faculty of Applied Informatics, Department of Automation \\ and Control Engineering, Nad Stranemi 4511, Zlin, Czech Republic
}

\begin{abstract}
This article describing newly build tract for measuring regenerative heat exchangers. At the beginning of this work is summarised measuring of heat recovery exchangers, parameters of heat recovery exchangers and conditions of measurements. This article continuous with the introduction of HVAC laboratory for which new track is built. Particular emphasis is on measuring box in which are exchangers measured.
\end{abstract}

\section{Introduction}

Regardless of the current economic problems of some EU countries, it is generally clear that the countries are continually striving to reduce energy consumption, both in the form of direct consumption of operating energy and energy invested in the production and disposal of buildings and equipment. According to the conclusions of the COP 21 conference held in Paris in 2015, almost 50\% of final energy consumption in the EU is used for heating and cooling, of which $80 \%$ is in buildings. The long-term strategy in this area is to ensure the lowest possible energy dependence of buildings in individual countries, preferably with energy production at the point of consumption, with emphasis on the complexity of energy-saving measures while maintaining a quality indoor environment, i.e., visual and thermal comfort. DIRECTIVE (EU) 2018/844 OF THE EUROPEAN PARLIAMENT AND OF THE COUNCIL of 30 May 2018 [1] amending Directive 2010/31 / EU on the energy performance of buildings and Directive 2012/27 / EU on energy efficiency effectiveness. The plan responds to the 3rd Directive 2018/844 / EU on the energy performance of buildings, which requires further reduction of the consumption of total (primary) energy in technical systems of buildings. Emphasis is placed on the complexity of cost-saving measures, which must not be limited to the insulation parameters of the building envelope, but all relevant elements and technical systems and reduce both energy consumption and increase the visual and thermal comfort of the indoor environment, both in new, as well as existing buildings. In our legislation, these requirements are reflected in Act No. 406/2000 Coll. on energy management as amended. The law requires that from 2020, all new state-owned buildings be in the NZEB (nearly zero energy) building. It is expected that all ventilation systems will be equipped with air heat recovery and that the energy consumption for lighting and cooling buildings will also be gradually

\footnotetext{
*e-mail: sehnalek@utb.cz

**e-mail: zalesak@utb.cz
} 
reduced. Following the requirements for the use of energy recovery in forced ventilation, the production of air recovery has increased and in this context also the need for their certification and thus also for the measurement of their parameters. For this reason, the laboratory of environmental engineering was extended to include a measuring duct for measurements on samples of regenerative heat exchangers, both in terms of production tests and tests required for product certification.

\section{Method of measuring energy and hydraulic parameters of recuperators}

The purpose of measuring the parameters of a regenerative heat exchanger (RHE) is to determine its primary energy parameter, and that is primarily its efficiency. Energy efficiency is defined, and its determination is given in the standard ČNN EN 308 [2]. The definition of the exchanger efficiency is based on the scheme shown in figure 1.

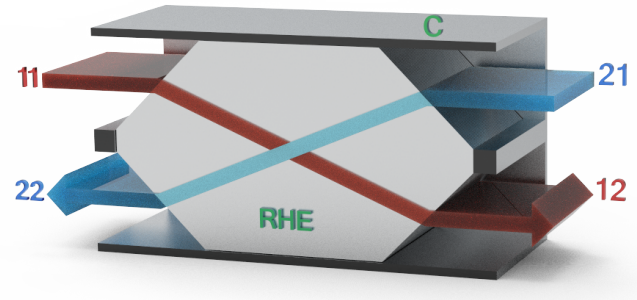

Fig. 1. Scheme of plate heat exchanger with box

In the figure 1 the numbers mean: 11 - Exhaust air inlet, 12 - Exhaust air outlet from the exchanger, 21 - Supply air inlet to the exchanger (for example from the outside environment), 22 - Exhaust air outlet from the exchanger, RHE - a regenerative heat exchanger and $\mathrm{C}$ - Measuring box.

The standard measurement conditions are based on CSN EN 308, where the exchangers are divided into categories according to the requirements placed on them. For standard winter conditions, the division is into two mandatory, three optional and for cold climates into one optional. Summer conditions are divided into four optional.

Measurements must be made at steady-state conditions of temperature, humidity and flow. However, the newly build test equipment is designed so that it is possible to perform research work on the construction of exchangers and is, therefore, more universal than is required by CSN EN 308 [2].

\subsection{The course of temperature and humidity parameters of air in exchangers}

The expected parameters of the measured heat exchangers are given in the table 1 . The performances are based on the most frequently used heat exchangers in domestic applications and on the possibilities of the equipment of the Laboratory of Environmental Engineering (LEE).

In order to determine the limit performance parameters of heat exchangers and thus also the requirements for the parameters of the test equipment, a computer 
Table 1. Performance parameters of measured elements

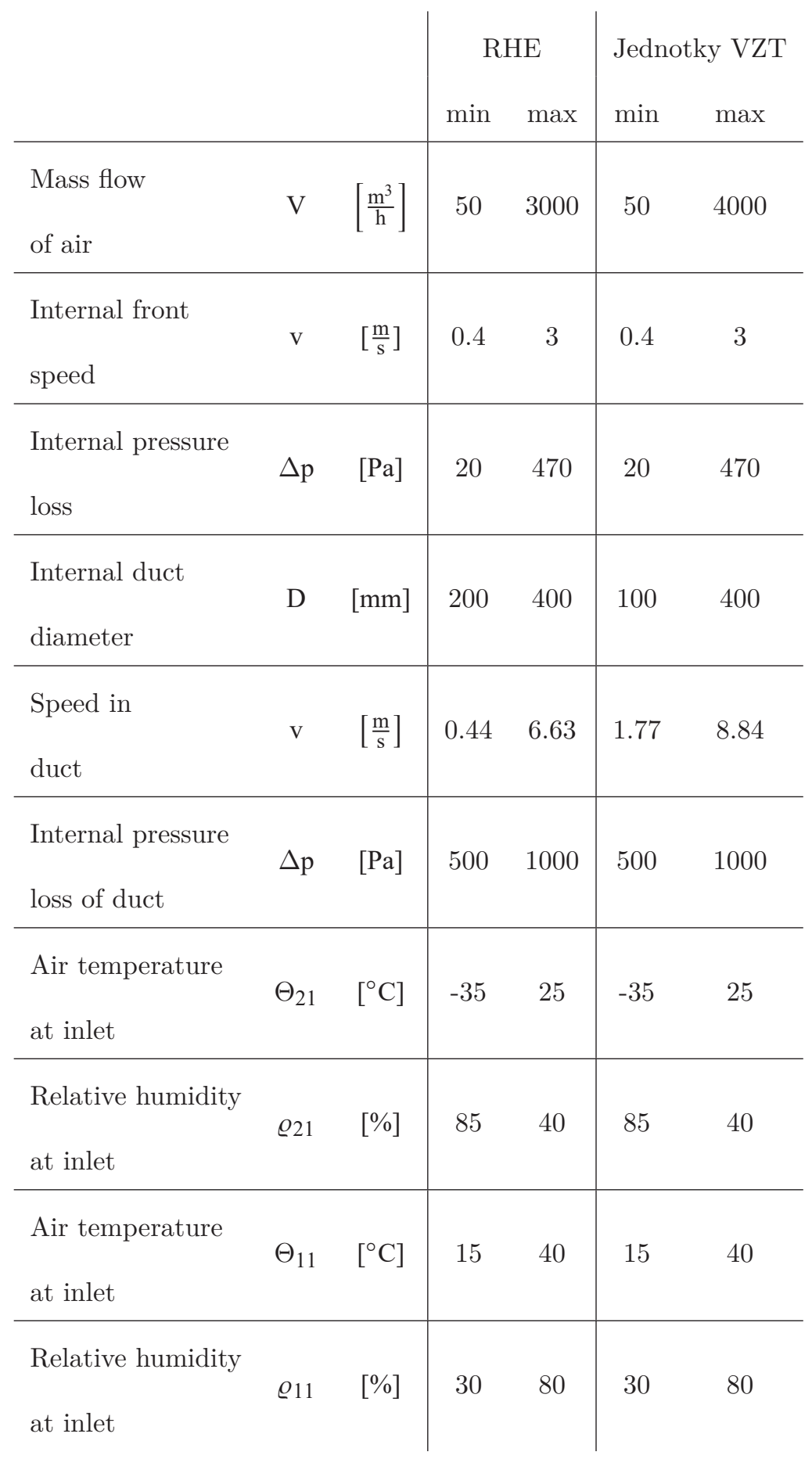




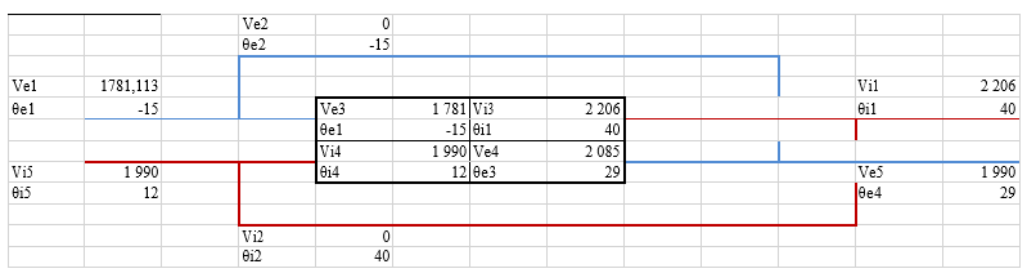

Fig. 2. Calculation scheme

Table 2. Example of entering the calculation of boundary conditions

\begin{tabular}{lll}
\multicolumn{3}{c}{ Temperatures } \\
$\Theta_{\mathrm{e} 1}$ & {$\left[{ }^{\circ} \mathrm{C}\right]$} & -15 \\
$\Theta_{\mathrm{e} 2}$ & {$\left[{ }^{\circ} \mathrm{C}\right]$} & 29 \\
$\Theta_{\mathrm{e} 3}$ & {$\left[{ }^{\circ} \mathrm{C}\right]$} & -15 \\
$\Theta_{\mathrm{e} 1}$ & {$\left[{ }^{\circ} \mathrm{C}\right]$} & \\
$\Theta_{\mathrm{i} 1}$ & {$\left[{ }^{\circ} \mathrm{C}\right]$} & 40 \\
$\Theta_{\mathrm{i} 2}$ & {$\left[{ }^{\circ} \mathrm{C}\right]$} & 40 \\
$\Theta_{\mathrm{i} 3}$ & {$\left[{ }^{\circ} \mathrm{C}\right]$} & -4 \\
$\Theta_{\mathrm{i} 4}$ & {$\left[{ }^{\circ} \mathrm{C}\right]$} &
\end{tabular}

Flows

$\mathrm{V}_{\mathrm{e} 1} \quad\left[\frac{\mathrm{m}^{3}}{\mathrm{~h}}\right] \quad 2000$

$\mathrm{V}_{\mathrm{e} 2} \quad\left[\frac{\mathrm{m}^{3}}{\mathrm{~h}}\right] \quad 0$

$\mathrm{V}_{\mathrm{e} 3} \quad\left[\frac{\mathrm{m}^{3}}{\mathrm{~h}}\right] \quad 2000$

$\mathrm{V}_{\mathrm{e} 4} \quad\left[\frac{\mathrm{m}^{3}}{\mathrm{~h}}\right] \quad 2000$

$\mathrm{V}_{\mathrm{i} 1} \quad\left[\frac{\mathrm{m}^{3}}{\mathrm{~h}}\right] \quad 2000$

$\mathrm{V}_{\mathrm{i} 2} \quad\left[\frac{\mathrm{m}^{3}}{\mathrm{~h}}\right] \quad 0$

$\mathrm{V}_{\mathrm{i} 3} \quad\left[\frac{\mathrm{m}^{3}}{\mathrm{~h}}\right] \quad 2000$

$\mathrm{V}_{\mathrm{i} 4} \quad\left[\frac{\mathrm{m}^{3}}{\mathrm{~h}}\right] \quad 2000$

program was developed for solving various situations during tests on heat exchangers in Excel. Figure 2 shows the scheme used for the calculation.

As an example, an entry containing the limit temperatures of the air entering the exchanger is given in the table 2 . The designations refer to the figure 2 . The results of the calculation are given in the table 3 .

\section{Elements of the test track of RHE}

The overall solution of the track can be divided into individual parts, which will then be described in detail.

- source section

- pipe section

- fan units

- box with measured sample

- measuring part 
Table 3. Calculation results according to the input from the table 2

\begin{tabular}{|c|c|c|c|c|c|c|c|c|}
\hline & $\begin{array}{c}\mathrm{qV}_{\mathrm{V}} \\
{\left[\frac{\mathrm{m}^{3}}{\mathrm{~h}}\right]}\end{array}$ & $\begin{array}{c}\Theta \\
{\left[{ }^{\circ} \mathrm{C}\right]}\end{array}$ & $\begin{array}{c}\varrho \\
{\left[\frac{\mathrm{kg}}{\mathrm{m}^{3}}\right]}\end{array}$ & $\begin{array}{c}\dot{\mathrm{m}} \\
{\left[\frac{\mathrm{kg}}{\mathrm{h}}\right]}\end{array}$ & $\begin{array}{c}\mathrm{q}_{\mathrm{m}} \\
{\left[\frac{\mathrm{kg}}{\mathrm{s}}\right]}\end{array}$ & $\begin{array}{c}\mathrm{h} \\
{\left[\frac{\mathrm{kJ}}{\mathrm{kg}}\right]}\end{array}$ & $\begin{array}{c}x \\
{\left[\frac{\mathrm{g}}{\mathrm{kg}}\right]}\end{array}$ & $\begin{array}{c}\text { Power } \\
{[\mathrm{kW}]}\end{array}$ \\
\hline $\mathrm{e}_{1}$ & 1781 & -15 & 1.35 & 2402.10 & 0.67 & -12.99 & 0.87 & \\
\hline$e_{2}$ & 0 & -15 & 1.35 & 0.00 & 0.00 & -12.99 & 0.87 & \\
\hline$e_{3}$ & 1781 & -15 & 1.35 & 2402.10 & 0.67 & -12.99 & 0.87 & \\
\hline$e_{4}$ & 2085 & 29 & 1.15 & 2402.10 & 0.67 & 31.52 & 1.01 & 29.67 \\
\hline$e_{5}$ & 2085 & 29 & 1.15 & 2402.10 & 0.67 & 31.52 & 0.87 & 29.67 \\
\hline$i_{1}$ & 2206 & 40 & 1.10 & 2433.80 & 0.68 & 76.67 & 14.8 & \\
\hline $\mathrm{i}_{2}$ & 0 & 40 & 1.10 & 0.00 & 0.00 & 76.67 & 14.08 & \\
\hline $\mathrm{i}_{3}$ & 2206 & 40 & 1.10 & 2433.80 & 0.68 & 76.67 & 0.87 & \\
\hline$i_{4}$ & 1990 & 12 & 1.22 & 2433.80 & 0.68 & 32.71 & 1.07 & -29.31 \\
\hline $\mathrm{i}_{5}$ & 1990 & 12 & 1.22 & 2433.80 & 0.68 & 32.71 & 8.16 & -29.31 \\
\hline
\end{tabular}

\subsection{Basis for track design}

\subsubsection{Test track parameters}

The design of the track is based on normative requirements for measurement on samples of regenerative heat exchangers and requirements for the possibility of measuring the parameters of RHE during development and research activities. From this analysis, the study of spatial limits in the LEE, also concerning the requirements for measuring the airflow and the expected range of power parameters of the exchangers, the initial parameters of the line design were determined. Assumed airflow parameters are $50 \mathrm{~m}^{3} \mathrm{~h}^{-1}$ to $4000 \mathrm{~m}^{3} \mathrm{~h}^{-1}$ at maximum pressure loss $2 \mathrm{kPa}$ of temperature ranges $-35^{\circ} \mathrm{C}$ to $+40{ }^{\circ} \mathrm{C}$ and relative humidity from $28 \%$ to $65 \%$. The primary air sources with the necessary parameters are the spaces of the compensated calorimetric chamber (CCC), from which the air is supplied and also returned. The only suitable place to place the track is the roof of the calorimetric chamber. This solution again requires modification of the chamber roof, i.e. the construction of the platform and the openings to the chamber roof. The exchanger in question is placed in a measuring box during the measurement. The boxing solution itself has a significant effect on the pressure losses of the track. During the solution, a series of modifications of the box necessary for the optimization of current conditions, to minimize pressure loss and the location of temperature and pressure sensors were performed. The performed analysis is the basis of the line design, including two-dimensional solutions for flow 


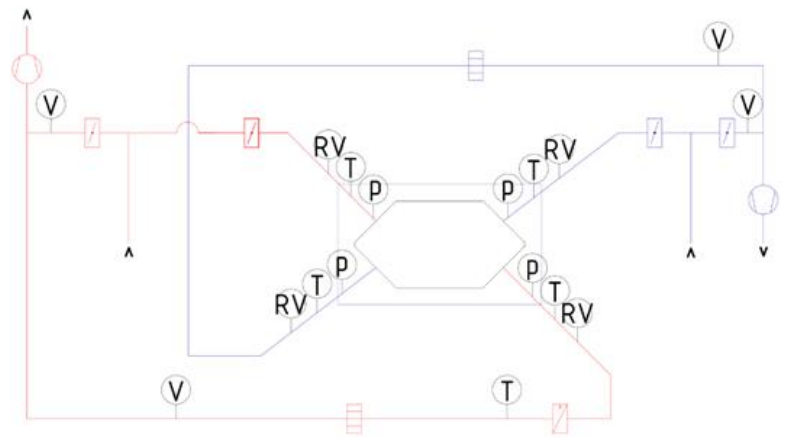

Fig. 3. Functional diagram of the tract, including measured parameters

measurement and the resulting spatial delimitation of passages for conditioned air inlets and subsequent passages for an air return to the CCC premises. Part of the design of the solution and implementation are necessary modifications of the ceiling structure of the calorimetric compensated chamber, on which the line is located.

\subsubsection{Basic test track scheme}

The functional scheme and principle of measurement including the measurement of parameters is shown in the figure 3 .

\subsection{Source part of the test track}

The source part of the test track is the existing combined compensated calorimetric chamber, which is designed as a universal, multi-purpose, with primary use for testing energy and acoustic parameters of refrigeration units, split systems, heat pumps and selected heating elements. The compensated calorimetric chamber is thus intended as a source of conditioned air for both parts of the recuperator. The compensated calorimetric chamber is divided into two parts with different climatic environments marked as part OUTDOOR (ODO) and INDOOR (IDO) and is located in the air-conditioned hall of the Environmental Technology Laboratory equipped with a manual 5t mobile crane to move samples of laboratory equipment and flexible parts of the chamber partitions and installations according to the type of tests performed. To maintain the parameters in the compensation spaces were made two special air conditioning units in the outdoor design with reinforced insulation, with special split exchangers, special evaporators, electric heaters with continuous control and fans with EC motors. The same temperature parameters must be maintained in the compensation rooms as in the relevant test rooms. For the IDO and ODO test rooms, select reconditioning units were again made with a particular combination of split heat exchangers and electronically controlled humidifiers with superior distribution for maintaining air temperatures with an accuracy of $\Theta s \pm 0,1 \mathrm{~K}$ and $\Theta \mathrm{m} \pm 0,3 \mathrm{~K}$. The fans are with EC motors and step-less speed control to maintain the volume flow with an accuracy of $\pm 1 \%$. In the IDO chamber it is possible to keep the air temperature in the range of $+5{ }^{\circ} \mathrm{C}$ to $+40^{\circ} \mathrm{C}$, in the $\mathrm{ODO}$ chamber it is possible to keep the air temperature in the range of $-25^{\circ} \mathrm{C}$ to $+40{ }^{\circ} \mathrm{C}$. The required combinations of maintained air temperatures and humidity for the various tests are given in the relevant standards. When 


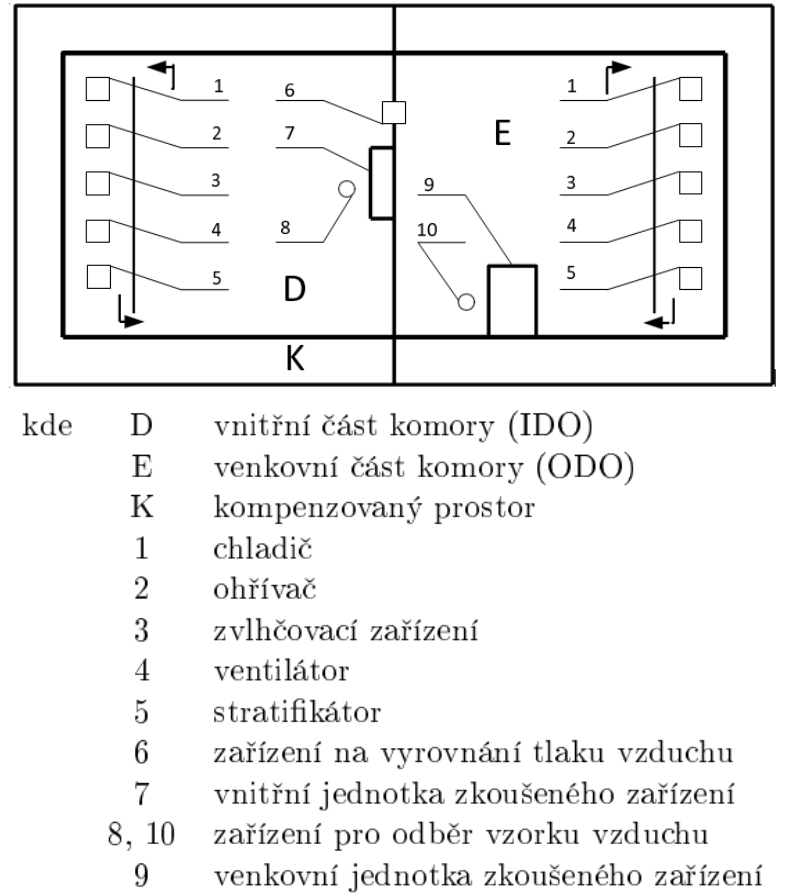

Fig. 4. Functional diagram of a compensated calorimetric chamber

confirming the chambers before the start of test operation in $09 / 2014$, the required accuracy of room temperatures of $\pm 0.1 \mathrm{~K}$ was achieved, after approximately 4-5 hours of stabilization of the operation of the chambers to the tested parameters.

\subsection{Sources of cold and heat}

A chiller with continuously controlled output is used as a source of cold for the water coolers of the compensation and reconditioning units of the chamber for charging the storage tank of the antifreeze mixture with a temperature gradient of $9 / 3{ }^{\circ} \mathrm{C}$. The antifreeze mixture is further regulated in subsequent circuits according to the needs of individual units. For temperatures below freezing, one condensing unit with a digital scroll compressor with stepless regulation is fitted and electronic injectors are installed for the individual evaporator sections of the respective units. The heat source is an electric boiler with storage tanks and subsequently controlled mixing circuits. The functional scheme of the chamber is shown in figure 4 .

The photo of the chamber is shown in the figure 5 and in the figure 6 the inner space of the ODO. The dimensional parameters of the chamber are given in the table 4. The performance parameters of the chamber are given in the table 5 .

\section{Tract part}

\subsection{Flow measurement}

The measured air flows at both branches are measured using orifices. Due to the wide range of transported air, the track was designed for two-dimensional variants, 


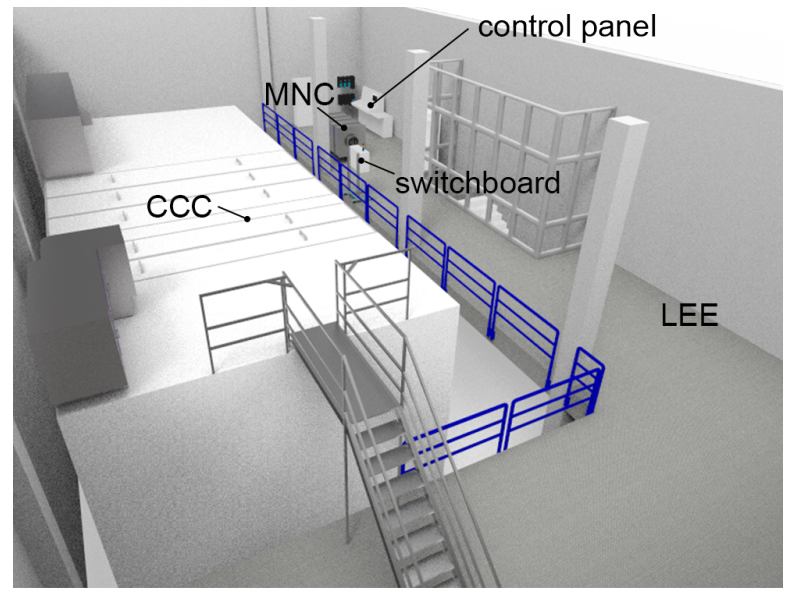

Fig. 5. Model of LEE with CCC

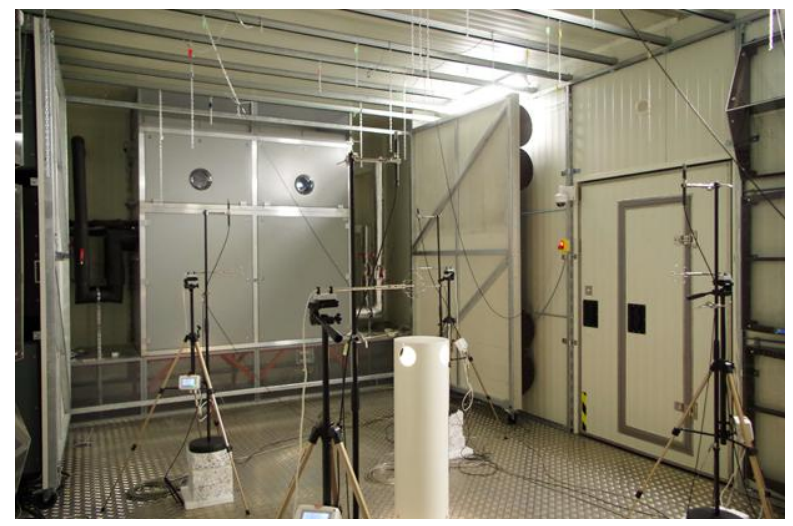

Fig. 6. A view of the outdoor part of the chamber when calibrating the partition

Table 4. Dimensional parameters of the compensated calorimetric chamber

$\begin{array}{lccccc} & & & \text { IDO } & \text { ODO } & \text { Total } \\ \text { Length } & \text { A } & {[\mathrm{m}]} & 4.0 & 8.0 & 13.45 \\ \text { Width } & \text { B } & {[\mathrm{m}]} & 4.3 & 4.3 & 5.64 \\ \text { High } & \text { H } & {[\mathrm{m}]} & 3.0 & 3.0 & 4.95\end{array}$


Table 5. Performance parameters of the chamber

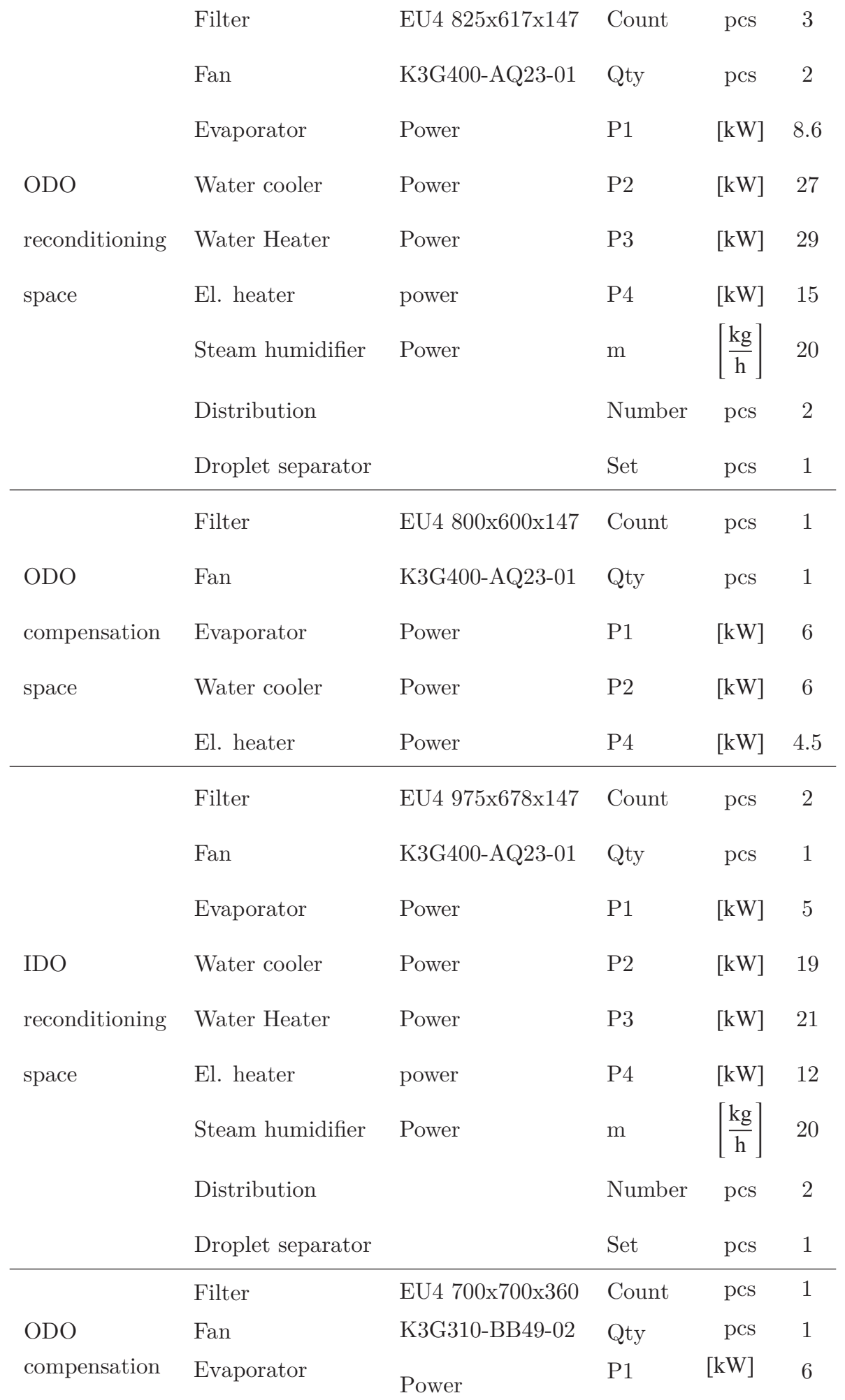


DN200 and DN400. The screens are manufactured in accordance with the normative requirements of CSN EN 5167-1 [3] and CSN EN 5167-2 [4]. They are made of stainless steel with angular pressure taps. Each orifice plate was subjected to a validation measurement of the orifice plate size, where for DN400 beta $=0.59765$ and beta $=$ 0.59763 and for DN200 it is beta $=0.61234$ and beta $=0.61237$. On both branches, the pressure difference between the atmospheric pressure and the vacuum in front of the orifice is measured separately, then also the pressure difference in front of and behind the orifice. Air temperatures in front of the curtains are measured using thermocouples.

The equation 1 is used to calculate the mass flow according to the standard.

$$
\mathrm{q}_{\mathrm{m}}=\frac{\mathrm{C}}{\sqrt{1-\beta^{4}}} \varepsilon \frac{\pi \mathrm{d}^{2}}{4} \sqrt{2 \Delta \mathrm{p} \varrho_{1}}
$$

$\begin{array}{llc}\text { where } & \text { flow factor } & {[-]} \\ \frac{1}{\sqrt{1-\beta^{4}}} & \text { input speed factor } & {[-]} \\ \beta & \text { ratio of orifice diameters } & {[-]} \\ \varepsilon & \text { expansion factor } & {[-]} \\ \Delta \mathrm{p} & \text { static pressure difference } & {[\mathrm{Pa}]} \\ \varrho_{1} & \text { air density in front of the screen } & {\left[\mathrm{kg} \mathrm{m}^{-3}\right]}\end{array}$

The expansion factor compensates for the fact that changes in the gas pressure during the flow through the differential pressure sensor lead to changes in its density. For nozzles and venturi tubes, the expansion factor can be calculated provided that the flow is adiabatic because it is limited by the walls of the meter. However, with screens, expansion occurs, which requires empirical determination of the values of the expansion factor. For an incompressible fluid, $\varepsilon=1$. In 1932, Buckingham [5] published the first equation for the coefficient of expansion derived from data collected in 1929 for natural gas. However, in the following years, an error was found in the original Buckingham equation and therefore it was corrected by Kinghorn [6] and subsequently by Seidl [7]. The final form was then given to the newly derived equation by Reader-Harris [8], from the analysis of data collected by Kinghorn and data from Seidl. Subsequently, this equation 2 was adopted in 2003 in a new revision of ISO 5167-2. However, the equation 2 is applicable only if $\frac{\mathrm{p}_{2}}{\mathrm{p}_{1}} \geq 0,75$. [9]

$$
\varepsilon=1-\left(0,351+0,256 \beta^{4}+0,93 \beta^{8}\right)\left[1-\left(\frac{\mathrm{p}_{2}}{\mathrm{p}_{1}}\right)^{1 / \chi}\right]
$$




\section{where $\beta$ ratio of diameters $\quad[-]$ \\ $\mathrm{p}_{1} \quad$ static pressure in front of the orifice $[\mathrm{Pa}]$ \\ $\mathrm{p}_{2} \quad$ static pressure behind the orifice $\quad[\mathrm{Pa}]$ \\ $x \quad$ isentropic exponent $\quad[-]$}

The flow factor can be obtained for any differential pressure sensor and any installation by calibrating it in a flowing fluid. For a specific orifice meter, the flow factor is a function of the Reynolds number. However, there are considerable savings if the flow factor can be predicted. Over the years of experiments, it has been found that the flow coefficient can be predicted within a defined uncertainty, provided that the orifice is designed within standards. If the flow factor is to be used for orifices without being calibrated in the flowing fluid, the flow factor is usually taken from the published flow factor equation. The flow coefficient equation for the orifice was derived from the same data as the expansion factor. The last accepted revision was published by Reader-Harris / Gallagher [8]. Its modified version for corner sampling is given in the equation 3. Like the expansion factor, this equation was adopted in the new revision of ISO 5168-2: 2003. [9]

$$
\begin{aligned}
C=0,5961 & +0,0261 \beta^{2}-0,216 \beta^{8}+0,000521\left(\frac{\beta 10^{6}}{\operatorname{Re}_{\mathrm{D}}}\right)^{0,7}+ \\
& +\left[0,018+0,0063\left(\frac{19000 \beta}{\operatorname{Re}_{\mathrm{D}}}\right)^{0,8}\right] \beta^{3,5}\left(\frac{\beta 10^{6}}{\operatorname{Re}_{\mathrm{D}}}\right)^{0,3}
\end{aligned}
$$

where $\operatorname{Re}_{\mathrm{D}}$ Reynolds number for pipe $[-]$

It is necessary to use an iterative procedure to calculate the mass flow because the flow coefficient is a function of the Reynolds number, which depends on the knowledge of velocity. Standard CSN EN 5168-1 [3] proposes the use of a linear algorithm, which leads to fast convergence. This algorithm is implemented in the Excel evaluation table created by the author of this work.

\subsection{Fixing lengths before orifice plate}

According to standard CSN EN 5167-2 [4], the straight lengths in front of the screen must be in values that exceed the spatial dispositions of the LTP. However, the standard also allows shorter settling lengths, provided that a flow straightener is used. A plate Zanker flow rectifier (DZUP) was selected for the track under construction. The production scheme for sizes DN400 and DN200 is shown in the figure 7, where the letters a to e indicate the individual holes. The number of holes is specified by the standard for the letters $\mathrm{a}=\mathrm{c}=4$ and for $\mathrm{b}=\mathrm{d}=\mathrm{e}=8$. The thickness of DZUP $\mathrm{t}_{\mathrm{z}}$ can be in the values $0.12 \mathrm{D} \leq \mathrm{t}_{\mathrm{z}} \leq 0.15 \mathrm{D}$, for LTP purposes the maximum thickness was used and thus for DN400 $\mathrm{t}_{\mathrm{z}}=60 \mathrm{~mm}$ and DN200 $\mathrm{t}_{\mathrm{z}}=30 \mathrm{~mm}$. Dural blocks were acquired as material for DZUP and subsequently machined, according to the drawing specification from the figure 7 . The figure 8 shows the duralumin blocks, the machining process and the result. The minimum length for installing the orifice from the 


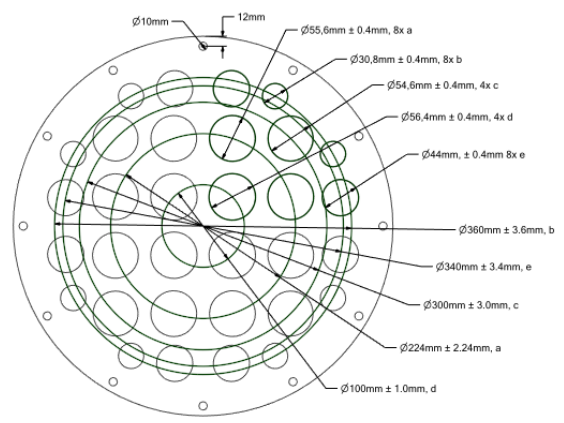

(a) DN400

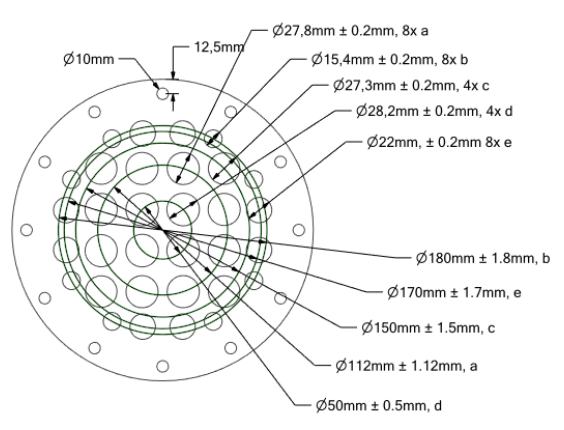

(b) DN200

Fig. 7. Drawings of DZUP for DN400 a DN200

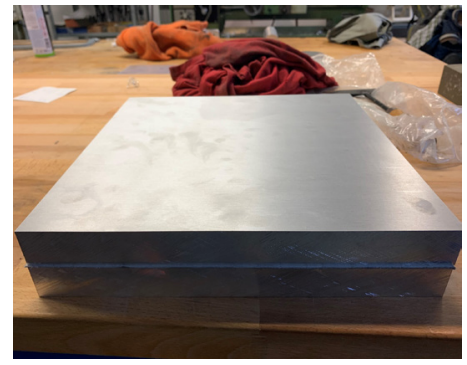

(a) Dural blocks

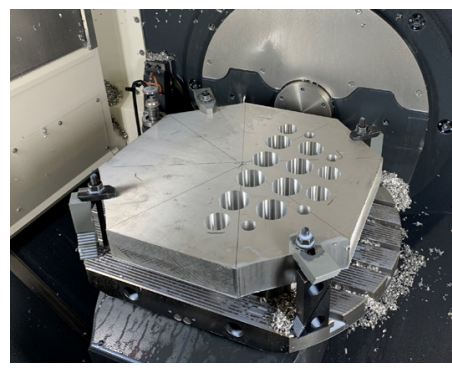

(b) Machining

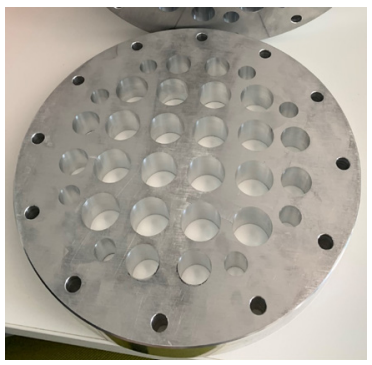

(c) Finished DZUP

Fig. 8. Manufacturing process of DZUP

last fitting using DZUP is $\mathrm{L}_{\mathrm{f}} \geq 17 \mathrm{D}$ and the length between DZUP and the orifice is specified as follows 7.5D $\geq \mathrm{L}_{\mathrm{s}} \geq \mathrm{L}_{\mathrm{f}}-8.5 \mathrm{D}$. According to standard CSN EN 5167-2 [4], the pressure loss coefficient for DZUP is equal to 3, where it is based on the equation 4. DZUP was measured for pressure loss and the average value of the pressure loss coefficient from the measurement is $\xi_{\text {DZUP }}=3.086$ which is in accordance with the standard due to the uncertainty of static pressure measurement.

$$
\xi_{\mathrm{DZUP}}=\frac{2 \Delta \mathrm{p}_{\mathrm{DZUP}}}{\varrho \mathrm{v}^{2}}
$$

kde $\xi_{\text {DZUP }} \quad$ DZUP pressure loss coefficient

$\Delta \mathrm{p}_{\text {DZUP }} \quad$ difference of static pressures before and after DZUP

$\varrho \quad$ air density

$\left[\mathrm{kg} \mathrm{m}^{-3}\right]$

v air velocity

$\left[\mathrm{m} \mathrm{s}^{-1}\right]$ 


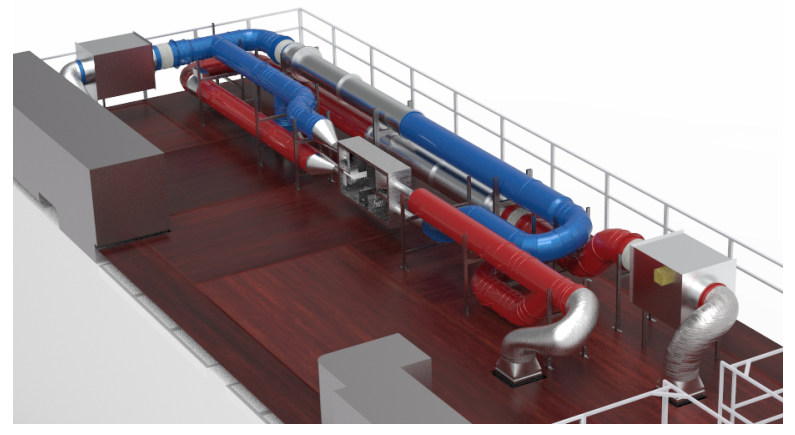

Fig. 9. Visualisation of final tract

\subsection{Box with measured RHE}

To measure the parameters of regenerative heat exchangers, it is necessary to mount the exchanger in a box that will meet specific parameters. One of the criteria is that the box comes as close as possible to its actual location during use. Another parameter of the box is the possibility of suitable placement of holes for taking static pressures. The box must be designed in such a way that there are no leaks between the individual sections and also the external environment. And the most critical parameter is that the box is sufficiently insulated so that there are no heat gains or leaks. A standard test box was purchased for the purpose of testing plate heat recovery exchangers. The box is designed according to the above-mentioned specifications with the possibility of placing various dimensional series of plate heat exchangers.

In figure 9 is visualisation of final tract for measurement.

\section{Conclusion}

The article deals with the issue of heat recovery, which follows the current trend in practice. It describes the line design procedure for measuring regenerative heat exchangers based on the required temperature, humidity and speed parameters. It describes the current state of knowledge about airflow and proposes the optimization of aerodynamic parameters of the recuperation box used for measurement. The work provides a summary of basic concepts in the measurement of regenerative heat exchangers.

This work was supported by the European Regional Development Fund under the project CEBIA-Tech No. CZ.1.05/2.1.00/03.0089 and also by the internal research project of RVO UTB for the year 2020 and also by the Internal Grant Agency of Tomas Bata University in Zlin under the project No. IGA/CebiaTech/2020/002.

\section{References}

[1] EUR-Lex - 32018L0844 - EN - EUR-Lex. https://eur-lex.europa.eu/eli/dir/2018/ 844/oj, 6 2017. (Accessed on 07/20/2020).

[2] CSN EN 308. Heat exchangers - Test procedures for establishing performance of air to air heat recovery components. Standard, Czech office for standards metrology and testing, Prague, 2009. 
[3] CSN EN ISO 5167-1. Measurement of fluid flow by means of pressure differential devices inserted in circular cross-section conduits running full - Part 1: General principles and requirements. Standard, Czech office for standards metrology and testing, Prague, 2003.

[4] CSN EN ISO 5167-2. Measurement of fluid flow by means of pressure differential devices inserted in circular cross-section conduits running full - Part 2: Orifice plates. Standard, Czech office for standards metrology and testing, Prague, 2003.

[5] Buckingham, E. Notes on the orifice meter: the expansion factor for gases. Proceedings of the flow measurement in the mid 80's, paper 5.2., 1986.

[6] Kinghorn, F. The expansibility correction for orifice plates: EEC data. Research paper no. 459, vol. 9, Bureau of standard journal research., Washington(DC), 1932.

[7] Seidl, W. Proceedings of the 3rd international fluid flow measurement symposium, Colorado engineering experiment station, 1995.

[8] Reader-Harris, M. FLOMEKO '98 : the 9th International Conference on Flow Measurement, June 15-17, 1998, Lund, Sweden : proceedings, Kista, Sweden, 1998. ITF.

[9] Reader-Harris, M. Orifice Plates and Venturi Tubes. Springer International Publishing, 2015. . ISBN 978-3-319-16880-7. 